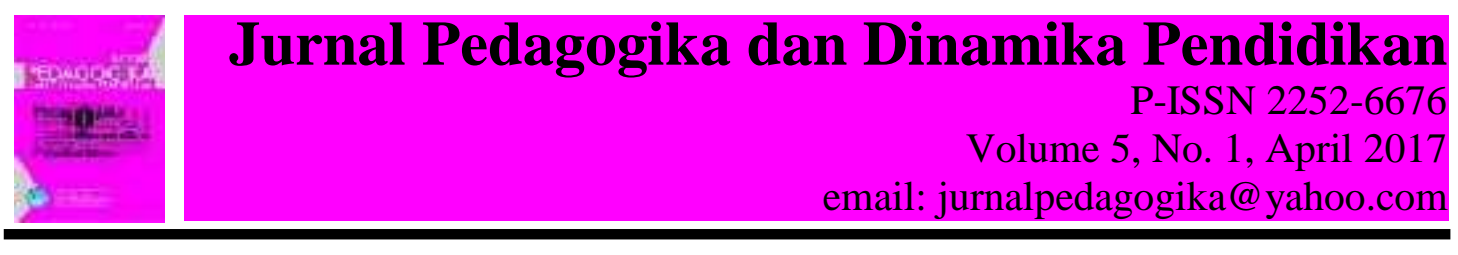

\title{
PERAN SELF REGULATION DALAM MENINGKATKAN KEMAMPUAN BERPIKIR KREATIF SEBAGAI UPAYA MENYIAPKAN GENERASI EMAS 2045
}

\section{Sri Hapsari}

Dosen Program Studi Pendidikan Ekonomi Universitas Indraprasta PGRI

\begin{tabular}{|c|c|}
\hline ARTICLE INFO & \multirow{13}{*}{$\begin{array}{l}\text { ABSTRACT } \\
\text { The purpose of this research is to determine the role of } \\
\text { self regulation in enhancing the ability of creative } \\
\text { thinking in social studies teaching and learning. } \\
\text { Therefore, the author conducted a survey on junior } \\
\text { high school in South Tangerang, Banten. Students ability } \\
\text { to organize themselves into an important key in } \\
\text { developing the ability to think creatively. Students will } \\
\text { know what you want to achieve so that he has a } \\
\text { conscious effort to focus the attention and the ability to } \\
\text { complete the task. Ability is what is required by } \\
\text { Indonesian golden generation because they will be } \\
\text { dealing with a very complex challenge. The golden } \\
\text { generation should be given so that the provision could } \\
\text { be responsible for the lives of himselfand his people. }\end{array}$} \\
\hline Article History: & \\
\hline Accepted 01 Maret 2017 & \\
\hline Available online 3 April 2017 & \\
\hline Keywords: & \\
\hline Self Regulation, Creative & \\
\hline Thinking, Golden Generation & \\
\hline & \\
\hline & \\
\hline & \\
\hline & \\
\hline & \\
\hline & \\
\hline
\end{tabular}

\section{PENDAHULUAN}

Sejak dahulu manusia dideskripsikan sebagai hewan berpikir (animal educandum) yang dimaknai sebagai manusia yang perlu dididik, agar ia dapat melaksanakan tugas hidupnya secara mandiri. Inilah yang membedakan manusia dengan makhluk lain. Tidak mengherankan jika Rene Descartes (1596-1650) dari kesangsiannya terhadap segala kebenarannya itu memunculkan diktum yang terkenal, "Aku berpikir maka aku ada (cogito ergo sum)" (Russell, 2007: 740). Menurut Descartes, dalam proses berpikir, ada sesuatu yang disangsikan. Dengan adanya 
kesangsian pada diri siswa, maka siswa akan berpikir, bagaimana menyelesaikan masalah yang ada, dan segera mengambil keputusan.

Siswa saat ini yang notabene adalah generasi emas Indonesia merupakan manusia abad 21, yang hidup dalam kondisi dengan perubahan yang sangat cepat dan tidak menentu sehingga potensi berpikir ini perlu dikembangkan secara berkesinambungan. Para siswa ini merupakan generasi penduduk warga dunia yang bersifat traskultural, namun harus tetap hidup dan berkembang dalam jati diri dan budaya Indonesia sebagai sebuah bangsa yang bermartabat (Kartadinata, 2012). Untuk itu, siswa harus memiliki kemampuan berpikir, khususnya berpikir kreatif guna menyikapi perubahan-perubahan yang bersifat dimensional.

Ada empat strategi yang digunakan sebagai pedoman untuk menetukan strategi proses pembelajaran dalam menyiapkan generasi emas 2045: pertama, pengembangan nasionalisme Indonesia; kedua, penguasaan skills abad 21; ketiga, penggunaan IT dan kolaborasi; keempat, kreativitas (Tilaar dalam Riyono, 2016). Nasionalisme sebagai sebagai semangat bangsa yang bangga sebagai bangsa Indonesia dan mampu memberikan kontribusi terhadap permasalahan-permasalahan bangsa. Generasi emas harus 'melek' terhadap permasalahan bangsa dengan tetap mempertahankan kearifan lokal, menghadapi globalisasi dengan glokalisasi, think globally, act locally.

Melalui berpikir kreatif ini, siswa dapat mengembangkan dirinya secara optimal serta meningkatkan kualitas hidup lingkungan sosial. Keterampilan berpikir kreatif ini merupakan salah satu tujuan dasar pelayanan pendidikan. Guilford mendefinisikan berpikir kreatif sebagai: "kemampuan untuk melihat bermacam-macam kemungkinan penyelesaian terhadap suatu masalah, merupakan bentuk pemikiran yang sampai saat ini masih kurang mendapat perhatian dalam pendidikan" (Munandar, 2012: 31). Selama ini, pendidikan hanya fokus pada berpikir logis dan mengabaikan arti penting berpikir kreatif. Siswa seolah dipaksa untuk satu suara dengan jawaban dari guru. Hal ini menyebabkan siswa lamban dalam berpikir kreatif. Padahal dalam berpikir kreatif, seseorang dituntut untuk dapat memperoleh lebih dari satu jawaban terhadap suatu persoalan dan untuk itu diperlukan imajinasi, intuisi, penemuan, orisinal, rasa ingin tahu, membuat prediksi, serta mencoba-coba (Fauziyah dkk, 2013; Nurmasari dkk, 2014). Sumbangan pemikiran kreatif ini akan menunjang kemajuan suatu bangsa. Kreativitas yang dimaksud adalah kreativitas konstruktif bukan destruktif, ataupun merusak tatanan nilai-nilai moral yang berlaku.

Selain itu, perlu disadari bahwa setiap manusia dilahirkan kreatif. Setiap individu dipenuhi dengan eksplorasi berpikir yang berbeda-beda. Namun realitanya, di sekolah minim diajarkan cara berpikir, "kita diajarkan agar menyalin apa yang dipikirkan oleh pemikir masa lalu" (Michalko, 2012: 4). Aktivitas pembelajaran dinilai hanya berpaku pada rutinitas yang melembagakan tradisi dan mengabaikan potensi siswa. 
Pola-pola pembelajaran tradisional ini membuat siswa kurang kreatif dalam menyelesaikan masalah. Hal ini bertentangan dengan pemahaman mengenai hak anak dalam memperoleh pembelajaran kreatif seperti yang diungkapkan Beetlestone (2012:57), "semua anak memiliki hak yang sama untuk menjadi kreatif dan untuk memiliki akses penuh pada kesempatan dalam bidang-bidang kreatif dari kurikulum". Siswa dibatasi untuk berpikir mengenai kemungkinan-kemungkinan lain dalam memecahkan masalah. Dengan demikian, imajinasi anak terbatasi dan minimnya ide orisinal, sehingga terbentuk pola mental menyederhanakan kompleksitas kehidupan. Hal ini dibuktikan dari hasil penelitian yang dilakukan oleh Kurjono (2012) mengenai sikap siswa yang mayoritas masih netral pada sikap kreatif sebagai berikut :

Tabel 1 Tanggapan Siswa Mengenai Sikap Kreatif

\begin{tabular}{|l|c|c|}
\hline \multicolumn{1}{|c|}{ Kategori } & Frekuensi & Persentase \\
\hline Sangat Positif & 14 & 4.06 \\
\hline Positif & 88 & 25.51 \\
\hline Netral & 134 & 38.84 \\
\hline Negatif & 93 & 26.96 \\
\hline Sangat Negatif & 16 & 4.64 \\
\hline Total & $\mathbf{3 4 5}$ & $\mathbf{1 0 0}$ \\
\hline
\end{tabular}

Sumber: Kurjono (2012)

Berdasarkan tabel di atas, menunjukkan bahwa sikap kreatif dianggap tidak penting untuk dimiliki. Bahkan di urutan kedua, tanggapan siswa terhadap sikap kreatif adalah negatif. Padahal dengan memiliki kreativitas, siswa mampu untuk "menoleransi ambiguitas, disonansi, inkonsistensi, dan hal-hal yang janggal” (Michalko, 2012: 5).

Untuk meningkatkan kemampuan berpikir kreatif ini maka siswa harus mampu mengatur dirinya. Self regulation sebagai bentuk pengawasan diri seseorang untuk mencapai tujuan. Untuk itu perlu persiapan diri. Self regulation pada hakikatnya adalah: "is an active, constructive process whereby learners set goals for their learning plan actions and monitor, regulate and control their cognition, motivation and behavior" (Oguz, 2012: 28). Self regulation ini sangat penting dalam membangun kepercayaan diri dan keterampilan siswa serta membangun kesadaran mereka dalam belajar.

Siswa yang mengatur diri tahu apa yang ingin mereka capai ketika belajar, baik melalui fakta-fakta yang spesifik, mendapatkan pemahaman konseptual yang luas tentang suatu topik. Biasanya siswa mengaitkan tujuan-tujuan mereka mengerjakan suatu aktivitas belajar dengan tujuan yang telah mereka tetapkan. Dalam pengaturan diri, mencakup proses-proses sebagai berikut: 
1) Penetapan Tujuan (goal setting).

2) Perencanaan (planning).

3) Motivasi Diri (self-motivation).

4) Kontrol Atensi (attention control).

5) Penggunaan Strategi Belajar yang Fleksibel (flexible use of learning strategies).

6) Monitor Diri (self-monitoring).

7) Mencari Bantuan yang tepat (appropriate help seeking).

8) Evaluasi Diri (self-evaluation).

Ormrod (2008: 38-39).

Dengan self regulation ini, siswa akan tahu apa yang ingin mereka capai dalam pembelajaran serta dapat membantu mempercepat siswa dalam melakukan adaptasi belajar (Hidayat, 2013). Siswa memiliki usaha sadar untuk memfokuskan perhatian dan kemampuan untuk menyelesaikan tugas belajar. Dalam rangka mewujudkan hal ini, diperlukan bantuan seorang guru yang dalam perspektif Vygotsky (Joyce dkk, 2011) dikenal dengan istilah scaffolding, yakni cara yang dapat diterapkan untuk membantu siswa memperoleh kontrol metakognitif secara maksimal.

Metakognitif ini menjadi pencirian masyarakat masa depan. Maka proses pembelajaran dan guru sangat penting dan strategis dalam memberikan bimbingan, dorongan, semangat, fasilitas kepada para siswa untuk memperoleh pengetahuan dan teknologi. Penguasaan IPTEK menjadi penekanan kompetensi yang harus dimiliki karena generasi emas harus 'melek' terhadap permasalahan bangsa dan semua ini diperoleh bila siswa memiliki self regulation dan kemampuan berpikir kreatif. Berdasarkan pemikiran di atas, penelitian ini bertujuan untuk mengetahui pengaruh self regulation terhadap kemampuan berpikir kreatif. Variabel self regulation dan berpikir kreatif dinilai relevan dimiliki oleh siswa selaku generasi emas dalam menghadapi tantangan global.

\section{METODOLOGI PENELITIAN}

Penelitian dilakukan di seluruh SMPN di Tangerang Selatan dengan jumlah sampel sebesar 401 siswa dengan teknik sampling proportionate random sampling. Karena ukuran sampel dari besarnya populasi dapat diketahui, maka penulis menggunakan ukuran sampel berdasarkan rumus Isaac dan Michael (Sugiyono, 2010:

69) sebagai berikut :

$$
S=\frac{\lambda^{2} \cdot N \cdot P \cdot Q}{d^{2}(N-1)+\lambda 2 \cdot P \cdot Q}
$$




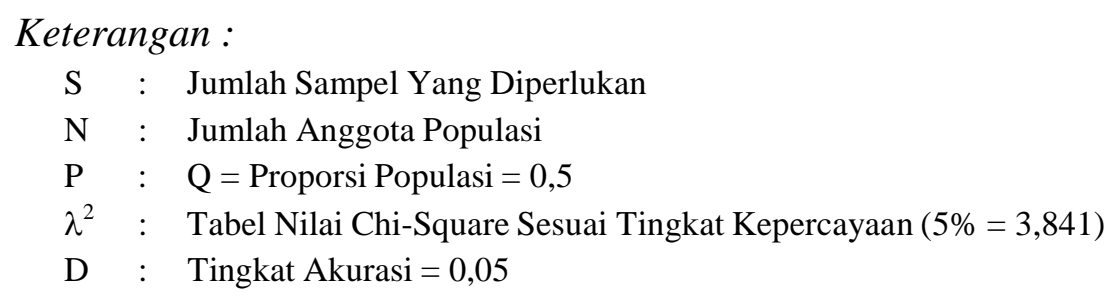

Berdasarkan formulasi di atas, dari jumlah populasi sebanyak 6753 dapat dihitung banyaknya unit sampel sebagai berikut :

$$
\begin{gathered}
\mathrm{S}=\frac{3,841 \times 6753 \times 0,5 \times 0,5}{0,05^{2} \times(6753-1)+3,841 \times 0,5 \times 0,5} \\
\mathrm{~S}=400,055(\text { Pembulatan } \\
\text { Menjadi } 401)
\end{gathered}
$$

Berdasarkan rumus di atas, diperoleh jumlah ukuran sampel sebesar 401 siswa SMPN di Kota Tangerang Selatan. Dari ukuran sampel minimal siswa dengan 401 responden, maka untuk pendistribusian sampel untuk masing-masing SMPN secara proporsional, maka dilakukan alokasi sampel berdasarkan perbandingan jumlah siswa yang tampak disajikan pada tabel di bawah ini :

Tabel 2 Jumlah Sampel

\begin{tabular}{|l|l|c|}
\hline \multicolumn{1}{|c|}{ SMPN } & \multicolumn{1}{|c|}{ Distribusi } & Alokasi Sampel \\
\hline SMPN 1 Tangsel & $452 / 6753 \times 401=26,80$ & 27 \\
\hline SMPN 2 Tangsel & $406 / 6753 \times 401=24,10$ & 24 \\
\hline SMPN 3 Tangsel & $449 / 6753 \times 401=26,66$ & 27 \\
\hline SMPN 4 Tangsel & $316 / 6753 \times 401=18,76$ & 19 \\
\hline SMPN 5 Tangsel & $355 / 6753 \times 401=21,08$ & 21 \\
\hline SMPN 6 Tangsel & $386 / 6753 \times 401=22,92$ & 23 \\
\hline SMPN 7 Tangsel & $301 / 6753 \times 401=17,87$ & 18 \\
\hline SMPN 8 Tangsel & $211 / 6753 \times 401=12,52$ & 12 \\
\hline SMPN 9 Tangsel & $267 / 6753 \times 401=15,85$ & 16 \\
\hline SMPN 10 Tangsel & $381 / 6753 \times 401=22,63$ & 23 \\
\hline SMPN 11 Tangsel & $352 / 6753 \times 401=20,90$ & 21 \\
\hline SMPN 12 Tangsel & $345 / 6753 \times 401=20,48$ & 20 \\
\hline SMPN 13 Tangsel & $349 / 6753 \times 401=20,72$ & 21 \\
\hline SMPN 14 Tangsel & $347 / 6753 \times 401=20,60$ & 21 \\
\hline SMPN 15 Tangsel & $307 / 6753 \times 401=18,22$ & 18 \\
\hline SMPN 16 Tangsel & $365 / 6753 \times 401=21,67$ & 22 \\
\hline SMPN 17 Tangsel & $294 / 6753 \times 401=17,45$ & 17 \\
\hline SMPN 18 Tangsel & $330 / 6753 \times 401=19,59$ & 20 \\
\hline
\end{tabular}




\begin{tabular}{|c|l|c|}
\hline SMPN 19 Tangsel & $207 / 6753 \times 401=12,29$ & 12 \\
\hline SMPN 20 Tangsel & $158 / 6753 \times 401=9,38$ & 9 \\
\hline SMPN 21 Tangsel & $175 / 6753 \times 401=10,39$ & 10 \\
\hline Jumlah & & $\mathbf{4 0 1}$ \\
\hline
\end{tabular}

Metode penelitian yang digunakan adalah metode kuantitatif, dikenal juga sebagai penelitian positivisme yakni bebas dari nilai, prasangka, dan subjektivitas. Pendekatan yang digunakan dalam peneltian ini adalah rancangan survey. Rancangan survei dipilih dalam penelitian ini dengan mempertimbangkan beberapa hal. Pertama, tujuan dari penelitian survei untuk menggeneralisasi populasi dari beberapa sampel sehingga dapat dibuat dugaan-dugaan sementara tentang karakteristik; perilaku; atau sikap. Kedua, rancangan ini dipilih karena dipandang ekonomis dan kecepatan dalam menyajikan data penelitian. Jenis survei yang dipilih adalah cross sectional survey, yakni mengumpulkan data satu per satu dalam satu waktu. Paradigma penelitian dapat digambarkan sebagai berikut :

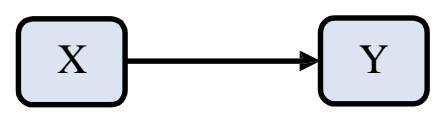

Variabel self regulation (X) dengan indikator-indikatornya adalah: (1) penetapan tujuan, (2) perencanaan, (3) motivasi diri, (4) kontrol atensi, (5) strategi belajar, (6) monitor diri, (7) mencari bantuan yang tepat, dan (8) evaluasi diri. Sedangkan berpikir kreatif (Y) dengan indikator-indikatornya adalah: (1) kelancaran dalam berpikir, (2) keorisinilan dalam berpikir, (3) kelenturan dalam berpikir.

\section{HASIL}

Responden pada penelitian ini adalah siswa kelas 8 SMPN di Kota Tangerang Selatan. Komposisi responden yang merupakan siswa SMP Negeri di Tangerang Selatan, dilihat dari jenis kelamin tampak pada tabel 3 :

\section{Tabel 3 Distribusi Responden berdasarkan Jenis Kelamin}

\begin{tabular}{|c|c|c|}
\hline Jenis Kelamin & Frekuensi (F) & Persentase (\%) \\
\hline Laki-laki & 160 & 39,91 \\
\hline Perempuan & 241 & 60,09 \\
\hline Jumlah & $\mathbf{4 0 1}$ & $\mathbf{1 0 0}$ \\
\hline
\end{tabular}

Berdasarkan tabel 3 di atas, menunjukkan bahwa responden penelitian sebagian besar atau $60,09 \%$ berjenis kelamin perempuan, hanya 39,91\% yang berjenis kelamin laki-laki.

Komposisi responden dilihat dari usia tampak pada tabel 4 di bawah ini : 
Tabel 4 Distribusi Responden berdasarkan Usia

\begin{tabular}{|c|c|c|}
\hline Usia & Frekuensi (F) & Persentase (\%) \\
\hline 12 tahun & 3 & 0,75 \\
\hline 13 tahun & 395 & 98,50 \\
\hline 14 tahun & 3 & 0,75 \\
\hline Jumlah & $\mathbf{4 0 1}$ & $\mathbf{1 0 0}$ \\
\hline
\end{tabular}

Meskipun usia kelas 8 sudah dapat diprediksi, namun demikian pada penelitian ini usia responden tidak seluruhnya sama. Tabel 4 menunjukkan bahwa responden penelitian ini lebih banyak berusia 13 tahun yaitu sebanyak 98,50\% yang dapat diperkirakan bahwa responden memasuki sekolah dasar pada usia 6 tahun. Responden yang berusia 12 tahun sebanyak $0,75 \%$ yang dapat diperkirakan bahwa responden memasuki sekolah dasar pada usia 5 tahun. Memang di beberapa sekolah dasar di Tangerang Selatan masih menerima usia siswa yang di bawah 6 tahun dengan syarat siswa tersebut sudah dapat membaca, menulis, dan berhitung. Sedangkan responden yang berusia 14 tahun sebanyak $0,75 \%$ yang dapat diperkirakan bahwa responden memasuki sekolah dasar pada usia 7 tahun. Sedangkan rata-rata kemampuan siswa dalam berpikir kreatif disajikan pada tabel 5 di bawah ini :

Tabel 5 Kemampuan Berpikir Kreatif SMPN Tangerang Selatan

\begin{tabular}{|c|c|c|}
\hline Jenis Keterampilan & Skor & Kriteria \\
\hline Kelancaran Berpikir & 3 & Sedang \\
\hline Kelenturan Berpikir & 4 & Tinggi \\
\hline Orisinalitas dalam Berpikir & 3 & Sedang \\
\hline
\end{tabular}

Hasil pengujian hipotesis disajikan pada tabel di bawah ini:

Tabel 6 Hasil Pengujian Hipotesis

\begin{tabular}{|l|c|c|c|}
\hline \multicolumn{1}{|c|}{ Path } & Standardized & $\mathbf{t}_{\text {hitung }}$ & Keputusan \\
\hline $\begin{array}{l}\text { Self Regulation (X) } \rightarrow \text { Berpikir } \\
\text { Kreatif }(\mathrm{Y})\end{array}$ & 0.872 & 9.692 & $\mathrm{H}_{0}$ ditolak \\
\hline
\end{tabular}

Dari tabel 6 di atas, dapat dilihat bahwa jalur memiliki nilai t hitung lebih besar dari 1,96 yang artinya terdapat pengaruh positif self regulation terhadap berpikir kreatif. Besar pengaruh disajikan dalam tabel 7 berikut :

Tabel 7 Pengaruh Self Regulation terhadap Berpikir Kreatif

\begin{tabular}{|c|c|c|}
\hline Path & Standardized & Pengaruh (\%) \\
\hline Self Regulation $\rightarrow$ Berpikir Kreatif & 0.872 & 76.04 \\
\hline
\end{tabular}




\section{PEMBAHASAN}

Hasil pengujian hipotesis, terdapat pengaruh self regulation terhadap berpikir kreatif sebesar 76,04\%. Hal ini membuktikan teori yang dikemukakan oleh Rhodes (Munandar, 2012) mengenai Four P's of Creativity yakni person, press, process, dan product. Salah satu faktor yang mempengaruhi proses kreativitas adalah person, artinya pribadi siswa ikut serta dalam pengembangan berpikir kreatif. Person disini dimaknai sebagai pemahaman individu (siswa) tentang hal-hal yang melatarbelakangi untuk membuatnya bertindak kreatif.

Siswa dengan self regulation tinggi, tahu apa yang ia butuhkan dalam pengembangan diri sehingga ia akan membuat manajemen diri. Self regulation erat kaitannya dengan self efficacy dari Bandura, yakni judgement seseorang atas kemampuannya untuk merencanakan dan melaksanakan tindakannya yang mengarah pada pencapaian tujuan tertentu (Mukhid, 2009). Sehingga apa yang siswa pikirkan, percayai, dan ia rasakan akan mempengaruhinya dalam bertindak. Jadi, self regulation ini menjadi press dalam siswa berpikir kreatif.

Siswa yang memiliki kemampuan mengatur diri, akan berusaha memfokuskan perhatian mereka pada pelajaran sehingga ia dapat menghasilkan ide-ide yang kreatif dan akan menggunakan banyak strategi untuk percapaian target. Kemampuan berpikir kreatif ini penting dikembangkan dalam pembelajaran karena sangat berguna bagi siswa. Siswa akan lebih mudah dalam mengemukakan pendapat serta memiliki banyak solusi dalam menyelesaikan masalah-masalah dalam hidupnya.

Tujuan yang ditetapkan disini adalah kemampuan untuk berpikir kreatif. Pendapat Ormrod (2008) ini juga senada dengan Delphi Panel bahwa tujuan dari pengaturan diri adalah: “to monitor one's cognitive activities" (Facione, 1990). Dengan melakukan monitor atas aktivitas yang dilakukan, siswa mengetahui, memahami, dan dapat menerapkan tujuan-tujuan. Siswa yang melakukan aktivitas kognitif dengan baik akan memperoleh pembelajaran yang bermakna, yakni mampu mengkonstruksi pengetahuan, termasuk memahami pengalaman-pengalaman mereka. Jadi aktivitas kognitif adalah cara-cara yang dipakai siswa secara aktif dalam proses mengkonstruksi makna (Anderson \& Krathwohl, 2010). Aktivitas tersebut meliputi mengingat, memahami, mengaplikasikan, menganalisis, mengevaluasi, dan mencipta.

Siswa dapat melakukan pengaturan pada dirinya dengan terlebih dahulu membuat perencanaan. Siswa merencanakan berbagi tugas-tugas belajar yang harus diselesaikannya, sehingga siswa dapat memanfaatkan waktunya sebaik mungkin. Saat di kelas, siswa yang memiliki self regulation yang tinggi, akan fokus pada materi yang sampaikan oleh guru. Dari sikap fokus ini, siswa tahu materi yang dapat ia pahami dan materi yang sulit dipahami. Dengan demikian, siswa dapat bertanya langsung kepada guru untuk menjelaskan. 
Pemahaman yang siswa peroleh melalui pengaturan dirinya yang baik, akan membantu siswa dalam berpikir kreatif. Berpikir kreatif sebagai regulator (Facione dalam Sdouh, 2013) artinya siswa yang memiliki regulasi tinggi pada dirinya, akan membuat siswa mudah dalam mengemukakan ide-ide. Sedangkan menurut Guilford (Supardan, 2015) berpikir kreatif sebagai representasi yang menekankan berpikir devergen daripada konvergen, memiliki sensitivitas yang tinggi terhadap masalah; kemampuan untuk melihat bermacam-macam kemungkinan penyelesaian terhadap suatu masalah.

Berdasarkan tabel 5 di atas, kemampuan rata-rata siswa dalam kelancaran berpikir kategori sedang. Keterampilan kelancaran berpikir (fluency) merupakan kemampuan untuk mencetuskan banyak gagasan, jawaban, penyelesaian masalah atas pertanyaan. Untuk mengukur kelancaran berpikir siswa, siswa diminta untuk menjabarkan berbagai cara untuk menyalurkan usaha kue agar sampai ke tangan konsumen. Dalam memasarkan kue dapat menggunakan perantara (distributor) maupun tanpa perantara. Dengan perantara, dapat bekerja sama dengan distributor kue di beberapa pusat perbelanjaan, toko-toko kue, kerja sama dengan beberapa catering. Sedangkan bila tanpa perantara, dapat membuka toko kue sendiri, dapat membeli ruko atau menyewanya untuk dijadikan tempat menjual kue, serta dapat bekerja sama dengan beberapa perusahaan atau kantor sebagai penyedia snack.

Kelenturan berpikir siswa SMPN di Tangerang Selatan berada pada kategori tinggi. Kelenturan berpikir merupakan kemampuan mencari banyak alternatif atau arah yang berbeda-beda, melihat masalah dari sudut pandang yang berbeda. Kemampuan siswa dalam berpikir lentur tampak pada kemampuan siswa dalam memilih jenis komunikasi yang digunakan agar lebih efektif dalam melakukan pembelian produk di luar kota. Mayoritas siswa memberikan jawaban memilih komunikasi dengan internet karena pembeli tidak harus datang ke lokasi penjualan terutama bila produk tersebut berada di luar kota. Selain itu, siswa diminta untuk mencari alternatif transportasi yang dapat digunakan untuk keluar kota namun dengan biaya rendah dan cepat sampai tujuan, kota yang dituju adalah Kebumen dengan lokasi asal Purwokerto. Purwokerto dan Kebumen adalah dua kota yang berada di provinsi Jawa Tengah, sehingga jaraknya masih terjangkau. Lokasi di jawa tengah mayoritas adalah daratan. Oleh karena itu, jenis transportasi yang tepat adalah transportasi darat. Selain itu, di kota ini masingmasing terdapat stasiun kereta api (KA). Maka KA menjadi transportasi alternatif/pilihan. Selain lebih cepat, aman, harganya pun relatif murah untuk tiket KA ekonomi. Dengan menggunakan KA, dapat cepat sampai di Kebumen, sehingga tidak memakan waktu, dan waktu liburan dapat digunakan sebaik-baiknya, dibandingkan dengan jenis transportasi darat lain seperti bus, angkot, taksi, dan sebagainya. 
Keterampilan ketiga dalam berpikir kreatif adalah orisinalitas dalam berpikir (originality) yakni kemampuan untuk mencetuskan gagasan dengan cara-cara yang baru; asli, membuat kombinasi yang tidak lazim, memikirkan hal yang tidak pernah terpikirkan oleh orang lain. Untuk mengukur originalitas berpikir siswa, siswa disajikan soal tes kontekstual yakni mengenai tanaman unggulan di Tangerang Selatan, Vanda Douglas. Siswa diminta untuk memberikan usaha-usaha yang dapat dilakukan agar budidaya anggrek ini dapat berkembang pesat serta memberikan dampak bagi pertumbuhan ekonomi di Tangerang Selatan.

\section{KESIMPULAN}

Self regulation berpengaruh terhadap berpikir kreatif. Hal ini memberikan makna bahwa semakin tinggi self regulation yang ada pada diri siswa, maka kemampuan berpikir kreatif yang ada pada diri siswa pun meningkat. Kemampuan berpikir kreatif diukur dengan kemampuan siswa dalam kelancaran berpikir, kelenturan berpikir, dan orisinalitas dalam berpikir. Kemampuan ini tidak hanya berasal dari dorongan dalam diri siswa namun diperlukan peran guru. Guru yang profesional akan mampu mengantarkan siswa menuju generasi emas Indonesia 2045, yakni generasi yang tetap berkembang dalam jati diri bangsa Indonesia. Untuk mengembangkan kemampuan berpikir kreatif, guru harus menghargai keunikan yang ada pada diri siswa. Guru harus memberikan kesempatan pada siswa dalam menyampaikan gagasan- gagasannya, guru tidak lagi mendominasi pembelajaran.

\section{DAFTAR PUSTAKA}

Anderson, Lorin W; Krathwohl, David R. (2010). Kerangka Landasan Untuk Pembelajaran, Pengajaran, dan Asesmen. Agung Prihantoro (penerjemah). Yogyakarta: Pustaka Pelajar.

Beetlestone, Florence. (2012). Creative Learning: Strategi Pembelajaran untuk Melesatkan Kreativitas Siswa. Bandung: Nusa Media.

Facione, Peter A. (1990). The California Critical Thinking Skills Test: College Level Technical Report \#1: Experimental Validation and Content Validity. Millbrae, CA: The California Academic Press.

Fauziyah, Isna Nur Lailatul; Usodo, Budi; Ekana Ch, Henny. (2013). Proses Berpikir Kreatif Siswa Kelas X dalam Memecahkan Masalah Geometri Berdasarkan Tahapan Wallas Ditinjau dari Adversity Quotient (AQ) Siswa. Jurnal Pendidikan Matematika Solusi. 1 (1): 75-89.

Hidayat, Akhmad Faisal. (2013). Hubungan Regulasi Diri dengan Prestasi Belajar Kalkulus II ditinjau dari Aspek Metakognisi, Motivasi, dan Perilaku. Jurnal Elektronik Pendidikan Matematika Tadulako. 1 (1): 1-8. 
Joyce, Bruce; Weil, Marsha; Calhoun, Emily. (2011). Models of Teaching: Modelmodel Pengajaran. Yogyakarta: Pustaka Pelajar.

Kartadinata, Sunaryo. (2012). Pendidikan Harus Antarkan Generasi Emas Indonesia 2045. Dalam ispi.or.id (diakses 19 November 2016).

Kurjono. (2012). Pengaruh Pengetahuan Kewirausahaan, Kompetensi Guru dan Lingkungan Keluarga terhadap Sikap Kreatif dan Sikap Inovatif serta Implikasinya terhadap Motivasi Berwirausaha. Dalam Disertasi. Bandung: UPI.

Michalko, Michael. (2012). Pemikiran Pemikir Kreatif: Melatih Imajinasi Anda. Ellys Tjo (penerjemah). Jakarta: Indeks.

Munandar, Utami. (2012). Pengembangan Kreativitas Anak Berbakat. Jakarta: Rineka Cipta.

Nurmasari, Nina; Kusmayadi, Tri Atmojo; Riyadi. (2014). Analisis Berpikir Kreatif Siswa Dalam Menyelesaikan Masalah Matematika Pada Materi Peluang Ditinjau Dari Gender Siswa Kelas XI IPA SMA Negeri 1 Kota Banjarbaru Kalimantan Selatan. Jurnal Elektronik Pembelajaran Matematika. 2 (4): 351-358.

Oguz. (2012). The Influence of Creation of Self Regulation Environment for Educating Visual Arts Teacher on Academic Success. Journal of Arts and Humanities (JAH), 1(2), pg. 27-41.

Ormrod, Jeanne Ellis. (2008). Psikologi Pendidikan Membantu Siswa Tumbuh dan Berkembang, jilid 2. Amitya Kumara (penerjemah). Jakarta: Erlangga.

Riyono, Ahdi. (2016). Generasi Emas dan Daya Saing Bangsa. Dalam Infomuria.umk.ac.id (diakses tanggal 28 November 2016).

Russell, Bertrand. (2007). Sejarah Filsafat Barat: kaitannya dengan kondisi sosiopolitik zaman kuno hingga sekarang. Sigit Jatmiko dkk (penerjemah). Yogyakarta: Pustaka Pelajar.

Sdouh, Walid Mahmoud. (2013). The Effect of Using the Strategies of Brainstorming and Computer Education in Academic Achievement and the Development of Creative Thinking Skills of Sixth Grade Students In Jordon and their Attitudes Towards Learning Mathematics. Dalam European Scientific Journal, vol. 9, no. 13, pg. 220-238.

Sugiyono. (2010). Statistika untuk Penelitian. Bandung: Alfabeta.

Supardan, Dadang. (2015). Pembelajaran Ilmu Pengetahuan Sosial: Perspektif Filosofi dan Kurikulum. Jakarta: Bumi Aksara. 